\title{
Gastric Fluid
}

National Cancer Institute

\section{Source}

National Cancer Institute. Gastric Fluid. NCI Thesaurus. Code C86998.

The fluid produced by the stomach glands, composed of gastric acids and enzymes. 